\title{
Preservation Analysis and the Brittle Book Problem in College Libraries: The Identification of Research-Level Collections and Their Implications
}

Janet Gertz, Charlotte B. Brown, Jane Beebe,
Daria D'Arienzo, Floyd Merritt, and Lynn Robinson

This article examines the brittle book problem in college libraries, priorities for treatment of brittle research materials, and the potential contribution of college libraries to national preservation efforts. Using a methodology based on Ross Atkinson's article "Selection for Preservation," the authors conducted condition surveys in three college libraries, identified titles as curriculum support, low-use research, or special collections materials, and assessed their physical condition. The results indicate that these three libraries own significant numbers of low-use research volumes which are brittle and in some cases held by few other libraries nationwide.

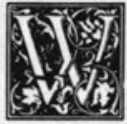

ithin the last decade, liberal arts college libraries in the United States have begun developing preservation programs for their collections.' ${ }^{1}$ For years, these libraries have carried out many of the components of a preservation program, such as item conservation treatments, user education, replacement, and rehousing of damaged materials. Until recently, however, most college libraries have not had a librarywide preservation program coordinated by an in-house preservation administrator.

Librarians generally do not question the need for all libraries, whether they are public, school, special, or academic, to make easily applied and commonsense preservation practices part of the library's operations. Proper materials handling, user education, and the training of staff in basic minor repairs produce immediate results and are easily accomplished with relatively little expense. Many librarians, including directors of liberal arts college libraries, do, however, question whether the collections of liberal arts colleges merit the substantial philosophical and financial commitment required for a full preservation program. They question the benefits derived from complex activities,

Janet Gertz is Director for Preservation, Columbia University, New York, New York 10027; Charlotte B. Brown is Assistant Head/Special Collections and University Archivist, University of California, Los Angeles, California, 90024-1575; Jane Beebe is Deputy Technical Services Director, Grinnell College, Grinnell, Iowa 50112-0811; Floyd Merritt is Reference Librarian and Daria D'Arienzo is Archivist of the College and Preservation Officer, Amherst College, Amherst, Massachusetts 01002; and Lynn Robinson is Technical Services and Catalog Librarian, Gonzaga University Law Library, Spokane, Washington 99220-3528. The research for this paper was partially funded by Council on Library Resources Grant CLR 843. 
such as revising the commercial binding contract to reflect the current Library Binding Institute standards, conducting condition surveys of selected collections, or monitoring and assessing the physical and environmental conditions of library facilities. ${ }^{2}$ Unquestionably, lack of funding and difficulty in finding and often training someone to carry out these activities are significant obstacles.

What is sometimes overlooked when questioning the worth of a preservation program is the less immediate monetary benefit and the inherent ethical values that a program promotes. For example, what is the library's obligation in prolonging the useful life of the collections, particularly periodicals, with respect to regional interlibrary loan use, or for participation in a formal or informal cooperative collection development scheme? What are the preservation obligations with respect to maintaining the library's known subject strengths? What are the collection management implications and obligations to the donor when gift collections containing physically endangered materials are acquired? What are the long-term monetary and intellectual benefits, and what is the most cost-effective method of maintaining a physically stable collection?

If the context of this discussion is changed from the campus to the region or nation, then the significance of the college's materials beyond short-term and immediate curriculum support comes into play. Do research-level materials of national import exist in college libraries? If so, are there enough of these materials to coordinate efforts with existing national cooperative preservation programs? Do college libraries have a responsibility for long-term or "permanent" preservation of such low-use, often out-of-scope materials?

These are the preservation concerns addressed in this article. To examine these issues, the authors conducted two preservation surveys at Amherst and Grinnell colleges in 1990 and one at Franklin and Marshall College in 1988. The results of these three studies carry implications for preservation at individual col- lege libraries and for national preservation efforts.

\section{BACKGROUND TO THE 1990 STUDIES}

In May 1985 the Shadek-Fackenthal Library of Franklin and Marshall College (F\&M) in Lancaster, Pennsylvania, implemented a librarywide preservation program modelled after that of Yale University. The program actively promotes coordination of preservation activities within collection management and development functions. ${ }^{3}$ By 1987 , numerous embrittled nineteenth-century titles in the classics collection were identified as in need of preservation decisions. ${ }^{4}$ At about the same time, Ross Atkinson had just published his article, "Selection for Preservation," describing a typology which analyzes titles for intrinsic value, intellectual value, and patterns of use. ${ }^{5}$ Charlotte B. Brown and Janet Gertz undertook a study blending Atkinson's typology with the preservation decision-making methodologies already in place at F\&M. They tested the new method in 1988 with a survey of the F\&M classics and linguistics collections. ${ }^{6}$

Not only did Atkinson's typology prove workable for F\&M, but the results of the survey indicated that 36 percent of the titles in the classics collection were of research value (Atkinson's Class 3-see Appendix for definitions); 42 percent of the collection was physically endangered; and 24 percent of the Class 3 titles were reported to be held by five or fewer other libraries. ${ }^{7}$ The study had identified a small but coherent group of materials with research value on a national level. The question then arose whether other liberal arts college libraries have subject collections that could produce similar results.

In spring 1989, the Council on Library Resources (CLR) funded a proposal to test the applicability of the F\&M methodology in the collections of Amherst and Grinnell colleges. The test would also determine if these two collections would exhibit profiles comparable to F\&M's despite differences in their histories and environments. The study's 
hypotheses maintained that the F\&M methodology would accurately record the physical condition of each title in the Amherst and Grinnell collections and unequivocally assign it to one of the three Atkinson classes, and that significant Class 3 materials would be identified in both collections.

\section{METHODOLOGY OF THE STUDIES}

The methodology used at F\&M, and later replicated by Amherst and Grinnell colleges, consisted of a random survey of volumes from designated subject areas, classification of each title according to Atkinson's typology, analysis of circulation records and physical condition, and identification of holdings of Class 3 materials outside the home library. Consistent evaluation of the books' physical condition was assured by using definitions and criteria established for the Yale preservation survey conducted from 1979 to $1982 .^{8}$ (See appendix for the definitions employed here).

Each randomly selected title, including all volumes and duplicate copies, was located in the stacks or retrieved from circulation and then inspected for physical condition. The investigators noted the number of circulations, as well as reserve and interlibrary loan uses since 1979 , and then classified the title according to Atkinson's typology. All titles which fell into Class 3 were searched in OCLC, RLIN, and NUC Pre56 to determine holdings nationwide.

Maintaining consistency between the methodology employed in the F\&M study and the subsequent Amherst/Grinnell project was essential to generating comparable data. The investigators from Amherst and Grinnell, therefore, met with Brown and Gertz to learn and practice the F\&M methodology and to modify as needed the coded survey worksheets. ${ }^{9}$

Summaries of the survey at Grinnell, conducted and reported by Lynn Robinson and Jane Beebe, and of the survey at Amherst, conducted and reported by Daria D'Arienzo and Floyd Merritt, follow. Complete details of the two case studies are available on request from the respective authors.

\section{FIRST CASE STUDY: SURVEY OF THE CLASSICS COLLECTION AT GRINNELL COLLEGE}

Grinnell College is an undergraduate, four-year, coeducational residential institution in Grinnell, Iowa, whose goal is for students to develop analytical and imaginative thinking in the liberal arts. The school has 33 academic departments and 129 faculty members. The faculty's primary mission is to teach. ${ }^{10}$

The college was founded in 1846 in the city of Davenport, Iowa, and was the first to grant a bachelor of arts degree west of the Mississippi River. In 1859, Iowa College, as it was called then, moved to Grinnell, Iowa, and was renamed Grinnell College. In 1882, a cyclone hit Grinnell, destroying both college buildings. Nevertheless, the structures were rebuilt and the curriculum was expanded.

\section{What is sometimes overlooked when questioning the worth of a preservation program is the less immediate monetary benefit and the inherent ethical values that a program promotes.}

The library collection has been housed in at least four separate locations." During the $1982-83$ school year, a major renovation and expansion of Burling Library doubled the study and shelf space, provided air conditioning throughout the building, and provided individual lighting systems.

The primary purpose of the collection is to support the curriculum and, secondarily, the basic research needs of the faculty. Burling Library holdings exceed 300,000 volumes and over 2,000 active serial titles. The college has been a selective United States depository since 1874 and is also a full depository for State of Iowa documents. Faculty and librarians share selection responsibility, and the annual acquisitions rate is approximately 9,500 volumes.

The library began a reclassification and retrospective conversion project in 
TABLE 1

COLLECTIONS COMPARED AS A WHOLE

\begin{tabular}{lrrrr}
\hline & \multicolumn{4}{c}{ Library and LC Class } \\
\cline { 2 - 5 } Percentage & $\begin{array}{r}\text { F\&M } \\
\text { P (\%) }\end{array}$ & $\begin{array}{c}\text { F\&M } \\
\text { PA (\%) }\end{array}$ & $\begin{array}{c}\text { Grinnell } \\
\text { PA (\%) }\end{array}$ & $\begin{array}{c}\text { Amherst } \\
\text { QE (\%) }\end{array}$ \\
\hline Atkinson class & & & & \\
Class 3 & 12 & 36 & 44 & 46 \\
Class 2 & 86 & 62 & 54 & 45 \\
Class 1 & 1 & 2 & 2 & 9 \\
Publication date & & & & \\
pre-1900 & 22 & 58 & 63 & 58 \\
pre-1950 & 88 & 42 & 37 & 30 \\
1950- & 6 & 33 & 26 & 22 \\
1980- & 32 & 1 & 9 & 86 \\
English language & 87 & 66 & 71 & 29 \\
Used since 1979 & 51 & 36 & 48 & 6 \\
Condition & & & & \\
$\quad$ Unusable & 8 & 42 & 7 & 27 \\
Brittle & 7 & 41 & 41 & \\
\hline
\end{tabular}

1978. The entire collection is now reclassed, converted to machine-readable form, barcoded, and available on INNOPAC, Grinnell's local online catalog. An extensive weeding project involving faculty and librarians was also undertaken, using basic bibliographic reference tools. ${ }^{12}$

\section{Selection of Classics}

Given its history and continuing importance, Grinnell's classics collection was selected for the survey project. Since its founding, Grinnell's students have pursued a strong traditional curriculum focused on intensive study of literary texts in their original languages. ${ }^{13}$ Four full-time faculty members teach Greek and Roman literature, history, and art. These individuals are among the most active in the library's acquisitions program. The library has not been the recipient of any major gifts or donations to the classics section.

\section{Methodology}

A file was created using INNOPAC to determine the number of items in the Library of Congress PA classification, and a random sample was generated from this base, using Minitab software. The file was then searched and records printed off according to the random sample. The printouts were attached to survey worksheets and the volumes were inspected. Class 3 items were searched on OCLC for Associated Colleges of the Midwest (ACM), state, and national holdings. When holdings listed in OCLC totalled fewer than ten, NUC Pre-56 and RLIN were also searched.

\section{Survey Results}

Selected Grinnell data are presented in the third column of tables 1,2, and 3 .

The Grinnell PAs can be characterized as an older, well-used collection; 63 percent were published before 1951 . In the past ten years, 48 percent of the collection has circulated at least one time. Most of the collection, 71 percent, is in English. Almost half of the volumes have become brittle, and more than 82 percent are printed on acidic paper. Altogether, 7 percent of the collection is not usable, because of physical deterioration.

Atkinson's typology indicates that 54 percent of the collection can be characterized as Class 2, and 2 percent as Class 1. Despite the weeding projects, 44 percent of the collection was designated as Class 3, implying that these materials are still considered of value to the library even though not recently circulated. In total, 85 percent of Class 3 had not been used since 1979, while 74 percent of 
TABLE 2

ATKINSON CLASS 2 COLLECTIONS COMPARED

\begin{tabular}{lcccc}
\hline & \multicolumn{4}{c}{ Library and LC Class } \\
\cline { 2 - 5 } Percentage & $\begin{array}{c}\text { F\&M } \\
\text { P (\%) }\end{array}$ & $\begin{array}{c}\text { F\&M } \\
\text { PA (\%) }\end{array}$ & $\begin{array}{c}\text { Grinnell } \\
\text { PA (\%) }\end{array}$ & $\begin{array}{c}\text { Amherst } \\
\text { QE (\%) }\end{array}$ \\
\hline Publication date & & & & \\
pre-1900 & 5 & 36 & 45 & 6 \\
pre-1950 & 95 & 64 & 55 & 94 \\
$1950-$ & 1 & 9 & 8 & 1 \\
1980- & 35 & 16 & 15 & 47 \\
English language & 91 & 81 & 94 & 99 \\
Used since 1979 & 54 & 57 & 74 & 57 \\
Condition & & & & \\
$\quad$ Unusable & 3 & 21 & 4 & 2 \\
Brittle & 1 & 20 & 24 & 4 \\
\hline
\end{tabular}

TABLE 3

ATKINSON CLASS 3 COLLECTIONS COMPARED

\begin{tabular}{|c|c|c|c|c|}
\hline \multirow[b]{2}{*}{ Percentage } & \multicolumn{4}{|c|}{ Library and LC Class } \\
\hline & $\begin{array}{l}\text { F\&M } \\
P(\%)\end{array}$ & $\begin{array}{c}\text { F\&M } \\
\text { PA (\%) }\end{array}$ & $\begin{array}{c}\text { Grinnell } \\
\text { PA (\%) }\end{array}$ & $\begin{array}{l}\text { Amherst } \\
\text { QE (\%) }\end{array}$ \\
\hline \multicolumn{5}{|l|}{ Publication date } \\
\hline pre-1900 & 65 & 94 & 85 & 79 \\
\hline pre-1950 & 35 & 6 & 15 & 21 \\
\hline 1950 & 38 & 70 & 44 & 47 \\
\hline $1980-$ & 0 & 0 & 1 & 1 \\
\hline English language & 60 & 37 & 25 & 76 \\
\hline Used since 1979 & 10 & 5 & 15 & 2 \\
\hline \multicolumn{5}{|l|}{ Condition } \\
\hline Unusable & 46 & 74 & 10 & 6 \\
\hline Brittle & 43 & 74 & 62 & 50 \\
\hline \multicolumn{5}{|l|}{ Held by 5 or fewer other } \\
\hline libraries & 14 & 24 & 5 & 10 \\
\hline
\end{tabular}

Class 2 had circulated at least once. Only 25 percent of the Class 3 long-term research materials were English-language, and 85 percent were published between 1850 and 1950. The Class 2 materials were predominantly English-language ( 94 percent) and relatively new (55 percent published since 1950 and 15 percent since 1980).

The condition of bindings and leaf attachment for the two classes do not correlate with age, as 4 percent of Class 2 and 10 percent of Class 3 items are in bad condition. A greater contrast appears with regard to paper brittleness, where 76 percent of Class 2 items are in good condition as compared to only 38 percent of Class 3. Unfortunately, both classes have a high level of acidic paper, indicating that Class 2 volumes will also become embrittled in time.

\section{CONCLUSIONS}

The Atkinson typology is workable; all titles in the Grinnell collection fit easily into the typology. Although Grinnell found a significantly lower percentage of Class 3 titles held by five or fewer libraries nationally than did F\&M (5 percent versus 27 percent), this type of analysis remains worthwhile. As financial resources fail to keep pace and as collection development becomes increasingly dependent upon regional re- 
source sharing, access to data on the breadth, depth, and condition of the holdings of regional institutions becomes vital. In Iowa, for instance, Grinnell is working together with other institutions to formulate a comprehensive state preservation plan. If each Iowa Private Academic Libraries (IPAL) member would undertake this type of study, a sound preservation plan could be devised.

The CLR project has provided Grinnell College with the rationale and structure for establishing a preservation program within the context of its collection management objectives. The collection development librarian has been designated preservation officer. Also, binding, repair, and replacement decisions are now being made using the Atkinson typology.

\section{SECOND CASE STUDY: SURVEY OF THE GEOLOGY COLLECTION AT AMHERST COLLEGE}

Amherst College was founded in 1821 for the "education of indigent young men of piety and talents for the Christian ministry." ${ }^{14}$ Coeducational since 1976, Amherst is now an independent liberal arts institution for approximately 1,600 undergraduates. From its beginning, mathematics and science accompanied religious and classical studies as a preparation nineteenth-century Christian ministers deemed essential to fulfill their responsibilities and "thwart opposition." Currently, Amherst has thirty academic departments and 160 faculty who are engaged in two primary activities: the education of undergraduates and research.

In 1965, Amherst and four neighboring institutions-Smith College, Hampshire College, Mount Holyoke College, and the University of Massachusetts at Amherst-formed Five Colleges, Inc., a consortium that provides a wide range of academic, social, and cultural opportunities. The Five-College Automated Library System allows users from any of the campuses access to catalog and circulation information from all member libraries. A direct borrowing agreement among the libraries is facilitated by a pickup and delivery system.
The Robert Frost Library, constructed in 1965, is Amherst's main library facility. There are also six branch librariesBiology, Geology, Mathematics, Science, Music, and Psychology. ${ }^{16}$ Holdings number more than 725,000 volumes, 327,000 microforms, and 74,000 government documents. ${ }^{17}$ Amherst adds approximately 17,000 volumes per year to its collection and has 3,961 serial subscriptions. To the fullest extent possible, the library supports the research requirements of its faculty and students, including the purchase of titles which strengthen the research-level collections.

The library began cataloging on OCLC in 1974. In 1988, in cooperation with the other Five College libraries, an online catalog and circulation system was introduced. Approximately 90 percent of Amherst's catalogued holdings are now reflected in the Five-College database.

\section{Almost half of the volumes have become brittle, and more than 82 percent are printed on acidic paper. Altogether, 7 percent of the collection is not usable, because of physical deterioration.}

Amherst's collection development policy states that the library provides a balanced, well-rounded liberal arts collection by acquiring materials to support the general curriculum, the range and depth required of interdisciplinary studies, and a substantial, if not complete, portion of faculty research. The materials are also to support the research requirements of honors students writing theses and others conducting independent study or special projects.

\section{SELECTION OF GEOLOGY}

The study and teaching of geology at Amherst document the historical development of the field during the nineteenth and twentieth centuries, and the history of United States higher education. The school's Geology Department continues to offer a strong curriculum, but the extent to which these strengths were re- 
flected in the library's holdings was unknown. The survey was expected to provide useful data.

Geology materials are housed in the Frost Library and the Geology Department Library. Prior to being moved to those libraries, the materials had been shifted and moved periodically as a result of building construction, retrospective conversion, reclassification, and transfers. It is possible that some of the collection was lost in a 1882 fire, and a 1938 hurricane.

Overall, from 12 to 46 percent of the materials are identified as relatively low-use, research-level items in four subject collections from three well-established colleges whose library collections were begun in the early to mid-nineteenth century. Half or more of these items are brittle, and anywhere from 6 to 74 percent are unusable.

A separate departmental collection seems to have been formed about 1850 . In 1950 , the more recent, actively used segments of the collection were moved to an unstaffed departmental library in the Pratt Museum and stored in locked glassfronted bookcases for security purposes. Access is provided to students through the department secretary and faculty using a charge system. A theft-detection system was installed in Frost in 1976; the Geology Department library has never had one. The latest inventory in the Frost Library, done in 1981, indicated that approximately eighty geology titles were missing. As of 1988, ninety volumes were missing from the department library. There is natural and fluorescent lighting, and no climate control system in Pratt. ${ }^{18}$

Most geology material has traditionally been selected by the faculty and purchased from an annual library allocation. Periodical recommendations are reviewed by the library director. Depository selections and gift decisions are made by the reference librarian, who consults with faculty as necessary. The head of acquisitions identifies and fills significant gaps whenever possible. The college archivist and the curator of special collections are responsible for the selection and addition of materials in their respective areas. Weeding has been minimal.

In addition to the 4,389 geology monographs and serial titles sampled, the library holds approximately 350 geology periodical titles and about 75,000 topographical and geological maps received from the United States Geological Survey. Over the years, many volumes from the personal libraries of Amherst's Geology Department faculty have been accessioned into the collection. ${ }^{19}$ A few titles considered to be rare or at risk are located in the Special Collections and Archives Department.

\section{METHODOLOGY}

The Dewey shelflist cards were numbered from 1 to 2,655 and the Library of Congress QE shelflist cards from 2,656 to 4,389 (omitting periodicals in both classifications). A random sample of 354 titles was taken from the 4,389 total. Each shelflist card was reproduced onto a worksheet and each volume was inspected. Items assigned to Class 3 were searched on OCLC for Five-College, state, and national holdings. When the OCLC total was below ten, further searching was done in NUC Pre-56 and RLIN.

\section{SURVEY RESULTS}

Selected Amherst data are shown in the fourth column of tables 1 to 3 . The results indicate that 48 percent of the geology titles surveyed were published before 1950; 30 percent date from before 1900; and 8 percent date from before 1850. Eighty-six percent of the collection is in English and approximately 66 percent of the publications are United States imprints. Ninety-four percent of the publications are generally in usable condition, although the paper is acidic in 69 percent of the surveyed volumes and already brittle in 27 percent.

The per title recorded use is low in comparison to Grinnell and F\&M: only 29 percent had been charged out since 1979. Factors that may account for this include the nature of the material (older 
science materials are not as likely to circulate as are older titles in the humanities); the relatively small number of users involved; and locked bookcases and incomplete circulation records in the Geology Department Library.

The proportion of the collection meeting the criteria for Class 3 was 46 percent, which is close to the 45 percent that fell into Class 2. Not all of the Class 3 publications are particularly old; half were published after 1900, presumably reflecting to some degree the comparatively rapid pace at which science books become outdated. Amherst's policy of cataloguing the Geological Survey Professional Papers as a series until 1982 may also have affected the results, since all 1,238 of the pre- 1982 volumes are represented by a single shelflist card that was not selected for the survey. After 1982 , each title was catalogued separately. The fifteen post-1982 samples that turned up in the survey met Atkinson Class 2 criteria.

There was no recorded use since 1979 for 98 percent of Class 3 titles. Of Class 2 titles, however, 57 percent had been used at least once since 1979. The physical condition of the two classes shows a clear contrast- -50 percent of the Class 3 titles are already brittle versus 4 percent of those in Class 2. Three times as many Class 3 titles as Class 2 titles proved to be unusable, although the numbers in both cases were low. Note that Class 3 titles are older and contain much of the foreign-language material. These findings, consistent with those of Grinnell and $F \& M$, were expected.

While almost all of the Class 3 titles are held elsewhere, 10 percent of these are held by five or fewer libraries and 19 percent by ten or fewer libraries. Although the 10 percent represents only twelve titles in the sample, it extrapolates to $\mathbf{2 0 0}$ for the catalogued geology collection as a whole.

Of the 354 items sampled, 41 percent were from the Geology Department Library. Seventy-four percent of Amherst's Class 2 titles are housed there, and they constitute 81 percent of that collection. By contrast, 83 percent of the Class 3 titles are located in Frost Library. One immediate result of this survey was the identification and transfer of nineteen titles from the open stack area to Special Collections.

\section{COMPARISON OF THE DATA RESULTS FROM THE THREE SURVEYS}

The results of all three studies are compared in tables 1 to 3 . Class 2 materials, the curriculum-support portion of the collection, can be characterized as having more recent publication dates, a predominance of English-language texts, and relatively high levels of use. Books circulate most frequently when they are new, and foreign-language materials are used less than English-language materials. The Class 3 titles, in contrast, are characterized by relatively low use, higher rates of foreign languages, and older dates of publication. The latter feature inevitably correlates with increasingly brittle paper.

Taken as a whole, each collection presents a distinctive profile. However, it can generally be said that the two F\&M collections contain a lower percentage of Class 3 materials than the Amherst and Grinnell collections, and that the F\&M PAs are in significantly worse condition. By far, F\&M PAs constitute the highest percentage of books determined to be unusable. While Grinnell's PA collection is of the same age and just as brittle, it has a much lower percentage of unusable books. This may be due, in part, to Grinnell's weeding and repair project, and to the presence of the very brittle Gonzalez Lodge gift collection at F\&M.

While Grinnell's PAs are slightly older than the other collections, the F\&M Ps are the youngest in terms of publication date; a third of the titles have been acquired since 1980. The Amherst collection has the lowest use level and the F\&M Ps use level the highest. ${ }^{20}$

If only Class 2 materials are considered, the two PA collections contrast with the $P$ and $Q E$ collections in having older publication dates and more brittle paper. The F\&M PAs are also in worse overall condition. The age of the PA col- 
lections is not surprising since the subject matter encourages continuing use of older materials. The Grinnell Class 2 PAs stand out, with almost 25 percent higher use than the other three collections (see table 2).

When the Class 3 materials are compared, the two classics collections, as may be expected, have much higher foreign language rates. Again the F\&M PAs are shown to be significantly older and in poorer condition than the others, although all four Class 3 collections inevitably have high brittleness rates. At the same time, many more F\&M PAs are held by five or fewer other libraries (see table 3).

Overall, from 12 to 46 percent of the materials are identified as relatively lowuse, research-level items in four subject collections from three well-established colleges whose library collections were begun in the early to mid-nineteenth century. Half or more of these items are brittle, and anywhere from 6 to 74 percent are unusable. Finally, from 5 to 24 percent of the Class 3 materials are reported held by five or fewer other libraries. These percentages translate into several hundred volumes per subject collection which are not only physically at risk, but are also close to unique in U.S. holdings. At the same time, these materials are presumably assigned the lowest priority for preservation in the libraries which own them.

\section{CONCLUSIONS}

These studies set out to investigate several questions. Is the model proposed by Atkinson applicable and workable for college and other libraries whose major emphasis is not doctoral-level research? What does its application tell us about the intellectual makeup and physical condition of college libraries? Can this knowledge help each library to develop priorities for meeting its local preservation responsibilities? Do the results of the surveys indicate that college libraries may also have a national contribution to make? What are some possible avenues to approach national participation in preservation activities?
The Atkinson model, intended for use by major academic research libraries, is also applicable and workable for college libraries. F\&M, Grinnell, and Amherst successfully applied it to smaller and larger areas of the collection. It provides a rational, reliable, and organized structure for distinguishing curriculum support materials from low-use research materials, and for determining the average physical condition of each group. From this starting point, the library can begin planning and prioritizing for preservation. The same data can also help in evaluation and revision of collection development policies by indicating what percentage of the collection is used and what percentage may be out of scope for the library's primary mission. On the purely practical side, the random sampling takes a relatively small amount of staff time.

Since pockets of Class 3 materials were identified in all three libraries, such materials may be expected in other college libraries as well, at least the older ones or those which have acquired substantial retrospective subject collections through donations or purchase. The level of paper embrittlement in these older materials is predictably high, but in two of the three libraries more of the volumes are still usable than are comparable materials in many large research libraries. Columbia University, for instance, found that 53 percent of its older classics, medieval, and renaissance history collections are unusable by the definition employed for the three surveys discussed here. ${ }^{21}$ Of national interest is the fact that some of the college library Class 3 materials appear not to be widely held, even by research libraries. They form a class of near-unique holdings, the preservation of which is not addressed by national efforts aimed primarily at large research libraries.

How does the college library calculate the preservation needs of its Class 3 materials against the requirement to keep the active part of its collections in usable shape? In theory, the first priority for treatment in any collection should be the item which is in greatest immediate danger-the volume which is both in use 
and structurally unsound (whether brittle or not). Use magnifies the damage and results in quicker destruction of the volume. By definition, most Class 3 materials are infrequently used at best. Therefore, they are of lower priority in terms of physical risk and collection development. ${ }^{2}$ The approach advocated here is the implementation of proper care and handling techniques, and the housing of materials under stable environmental conditions. These methods of preservation can significantly delay further damage.

While this approach would appear to be a low-effort, no-cost solution, the cost of shelf space is high. Especially in a crowded facility, weeding emerges as a tempting alternative to long-term storage of unused, out-of-scope volumes. The results of this study, however, indicate that it may be worthwhile to search the national databases to determine what potential withdrawals are held by a large enough number of other libraries. This would ensure that one of the nation's last copies of a publication is not being eliminated.

It is not unusual for college libraries to have computer access to virtually all of their holdings. As they enter Class 3 titles into the national databases, college libraries contribute to national preservation efforts by making their holdings known and permitting other libraries to borrow volumes for microfilming in lieu of missing or severely damaged copies. Allowing the item to be borrowed for filming not only preserves the lender's copy (usually the borrower provides the lender with a copy of the film) but it also permits creation of a master negative available to the rest of the nation.

Where a substantial or coherent group of Class 3 materials exists, such as F\&M's Gonzalez Lodge Collection, there is the potential for grant funding. One model for cooperative filming is the 1990-92 SOLINET/ASERL Cooperative Preservation Microfilming Project in which a central agency handles the entire operation (bibliographic control, physical preparation, contracting with filming vendors, and film quality control) for libraries of various sizes. Participants then deposit their master negatives centrally. ${ }^{23}$ This minimizes the drain on local library staff, who need only deal with selection of the materials to be filmed.

The first step is to establish a local preservation program that can evaluate the collection, establish binding and repair policies that meet national guidelines, and keep the active part of the collection fully usable. This includes systematic, ongoing identification of any volumes damaged in use (at the point of circulation or when reshelving) and recommending appropriate treatment, whether rebinding, repair, replacement, reform- ation, or withdrawal. The local preservation program will also carry on preventive measures such as disaster preparedness, stack maintenance, training of staff and users in proper care and handling, and monitoring and improving the building's environmental conditions.

The second step, once unused Class 3 materials are identified, is to stabilize the materials physically. This may be as simple as cleaning and straightening the shelves, or it may involve rehousing or transferring volumes to closed storage to protect them from further harm. Withdrawal may also be an appropriate action. The third step is to participate "passively" in national preservation efforts by making the library's holdings known and by permitting borrowing for preservation purposes.

Taken as a whole, these three steps target local needs and reflect the library's basic responsibility to minimize damage to the collections, to keep them usable, to stabilize volumes which cannot be rebound or repaired, and to establish priorities which optimize use of preservation funds and staff time. The fourth step goes beyond local concerns and initiates reformatting of the Class 3 materials. This decision not only depends on the library's resources and priorities, it also involves a substantial commitment of time, seeking potential partners, grant writing, and implementation. The results, though, may well be a direct contribution to national, and indeed international, efforts to preserve our written heritage. 


\section{REFERENCES AND NOTES}

1. "Although it is notoriously difficult to adequately define a college library, for the most part these libraries share the following common factors: finite collection size (generally well under one million); small student body (usually about 2,000); principal focus on undergraduate students and instructional programs; secondary focus on research needs of the faculty; small materials budget (again, well under \$1 million); library staff of two to fifteen professionals; and the absence of subject bibliographers on the library staff." Joanne Schneider Hill et al., eds., Collection Development in College Libraries (Chicago: ALA, 1991), Introduction, $v$.

2. Paul A. Parisi and Jan Merrill-Oldham, eds., Library Binding Institute Standard for Library Binding, 8th ed. (Rochester, N.Y.: Institute, 1986); and Jan Merrill-Oldham and Paul A. Parisi, Guide to the Library Binding Institute Standard for Library Binding (Chicago: ALA, 1990).

3. For a description of the F\&M program see Charlotte B. Brown, "The Preservation Program at Franklin and Marshall College," Conservation Administration News 30(July 1987): 6-7.

4. These included F\&M's Gonzalez Lodge Collection of nineteenth-century embrittled classics titles. See Charlotte B. Brown and Kathleen M. Spencer, "Preservation: A Critical Element of Collection Development in College Libraries" in Collection Development in College Libraries, Joanne Schneider Hill, et al., eds. (Chicago: ALA, 1991), 173-74.

5. Ross Atkinson, "Selection for Preservation: A Materialistic Approach," Library Resources and Technical Services 30 (Oct./Dec. 1986): 341-53; as modified by Margaret Child, "Further Thoughts on 'Selection for Preservation: A Materialistic Approach,'" Library Resources and Technical Services 30 (Oct./Dec. 1986): 354-62.

6. Charlotte B. Brown and Janet Gertz, "Selection for Preservation: Applications for College Libraries" in Building on the First Century: Proceedings of the Fifth National Conference of the Association of College and Research Libraries (Chicago: ALA, 1989), 288-89.

7. Ibid., tables 4, 3, and 7, 292-94.

8. Gay Walker et al., "The Yale Survey: A Large-Scale Study of Book Deterioration in the Yale University Library," College \& Research Libraries 46(Mar. 1985): 111-32. One of the authors of the F\&M study participated in the Yale survey and was trained in its procedures.

9. Funding for the training sessions was included in CLR Grant 843. Copies of the work sheet are available from Gertz and Brown.

10. Grinnell College, Catalog, 1990-91 (Grinnell, Iowa: Grinnell College, 1990), $i$.

11. In 1859, the books were transported to Grinnell. In 1884, Goodenow Hall was built as the library and astronomical observatory. Carnegie Library was built in 1904 and Burling Library in 1959.

12. Over 25,000 volumes were withdrawn during the reclassification and conversion project. Weeding continues as an ongoing activity which removes several hundred volumes per year.

13. Grinnell College, Catalog, 1990-91, 72.

14. Charity Fund of Amherst College, Constitution and Bylaws (Amherst, Mass.: Amherst College, 1881), 1.

15. Donald Engley, The Emergence of the Amherst College Library 1821-1911 (master's diss., University of Chicago, 1947): 42-43.

16. The Amherst Library has been housed as follows: rooms in South College, North College, and Johnson Chapel, 1821-52 (1-10,000 volumes); Morgan Library, 1853-83(10,000-43,000 volumes); Morgan Library Addition, 1883-1917 (43,000-100,000 volumes); Converse Memorial Library, 1917-38 (100,000-225,000 volumes); Converse Memorial Library Addition, 1938-65 (225,000 volumes-400,000 volumes); Robert Frost Library, 1965-present (400,000-700,000+ volumes); 1990-early planning stages of Frost Library addition.

17. Amherst has held depository status since 1884 .

18. Daily weather records for 1990 show that the temperature at the college dipped as low as -4 degrees Fahrenheit on February 26, 1990 and soared as high as 95 degrees Fahrenheit on August 4, 1990.

19. These include Amherst professor and president Edward Hitchcock (1793-1864), the first president of the Association of American Geologists; Charles Upham Shephard 
(1804-1886), a nationally prominent member of the Geology faculty; Benjamin K. Emerson (1842-1930; AC 1865), best known for his writings on the geology of the Connecticut Valley and the plateaus of central and southern New England, and the first at Amherst to clearly separate geology from religion.

20. These studies did not investigate the ratio of student subject majors to subject collection size, nor differences in teaching styles with greater or lesser emphasis on library use.

21. Based on an item-by-item inventory of 161,000 volumes carried out in 1990 as part of the Foundations of Western Civilization Preservation Project funded by the National Endowment for the Humanities.

22. Consider the statement in Peter Sparks' recent research summary test that 'brittle book paper ( 1 fold or less) will not fall apart if the volume is left unused on the shelf year after year." (Peter G. Sparks, "Some Thoughts on Paper as an Information Storage Medium," Newsletter of the Commission on Preseroation and Access 40 (Nov./Dec. 1991): 3-4. This supports arguments for establishing a use-based approach to preservation such as those presented in Scott Bennett, "Buying Time: An Alternative for the Preservation of Library Material," ACLS Newsletter 3 (Summer 1991):10-11.

23. This National Endowment for the Humanities-supported project involves twelve members of the Association of Southeastern Research Libraries (ASERL) in cooperative filming of 17,000 volumes through the central Southeastern Library Network (SOLINET) Preservation Microfilm Service.

\section{APPENDIX ATKINSON'S TYPOLOGY DEFINITIONS*}

\section{Class 1 Preservation}

Materials having a high economic value, particularly special collections items, and level-five collections. Child modifies Atkinson's criteria by including items with intrinsic value. ${ }^{+}$The criteria for inclusion in this class were imprint date (foreign imprints pre-1801, United States imprints pre-1860); local publications for each of the participating institutions, such as for F\&M Pennsylvania imprints pre-1900 and all Lancaster County, Pennsylvania, imprints; notable first editions; editions limited to 500 or fewer; important association and signed copies; notable physical traits, such as fine bindings; and particularly high monetary value.

\section{Class 2 Preservation}

"Higher use items that are currently in demonstrable demand for curriculum and research purposes." $\ddagger$ Criteria used to identify these materials were relevancy of the title's subject content to current or anticipated curriculum and faculty research areas; assignment to a reserve section for any period during 1979-1988; circulation since 1979; and inclusion in a reference collection.

\section{Class 3 Preservation}

Lower-use research materials. Criteria used to identify these items were long-term intellectual value, and failure to fit into Class 1 or $2 .^{5}$

* Atkinson, 344-48.

+ Child, 355. Intrinsic value, as defined by Child, "encompasses several nonmonetary but important research values deriving from artifactual characteristics which compel preservation in the original format."

‡ Atkinson, 346 .

$\S$ Intellectual value is defined as the content of the item (such as words and pictures) created by the author, as distinguished from the form the item takes. A book and its photocopy are often said to have the same intellectual content, although, clearly, the photocopy has lost many of the physical attributes of the original book. 


\section{PHYSICAL CONDITION DEFINITIONS}

\section{Unusable}

. Any one aspect of the volume's physical condition is nonfunctional. The criteria used were:

- External protection (binding) is broken so that a cover or the spine is detached.

- Text block is broken or sewing/adhesive is broken.

One or more leaves is detached or significant portions of leaves are missing.

- Mutilation or environmental damage has caused one of the problems above or has caused portions of the test to become illegible.

\section{Brittle Paper}

Paper cannot survive two double-folds.

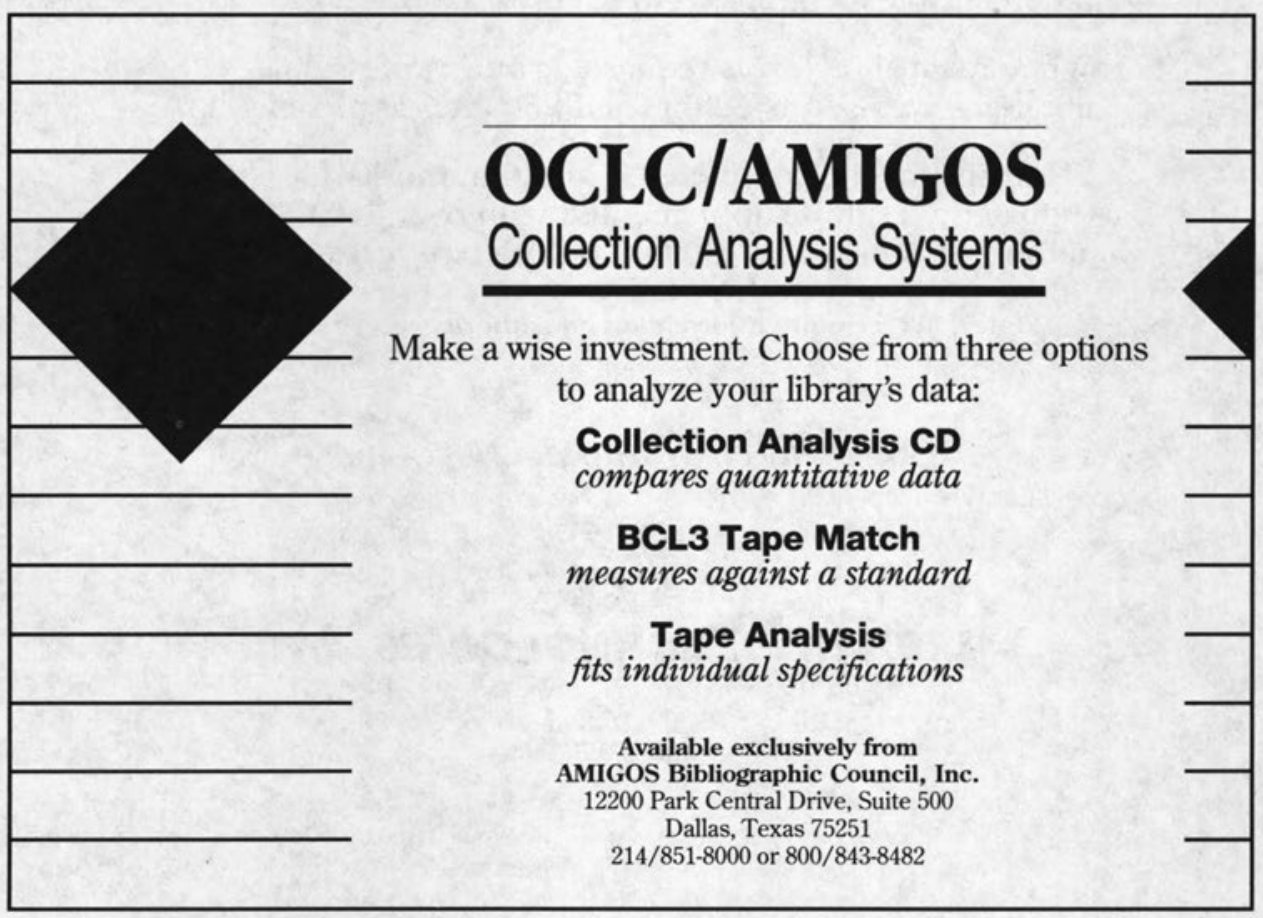




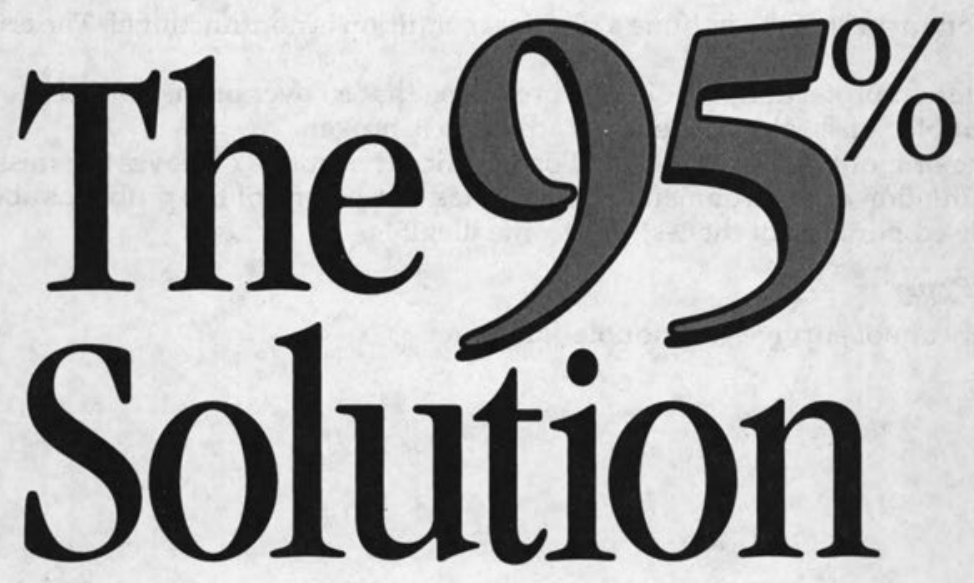

You get one chance with authority control, so it's important to get it done right. LTI guarantees that its affordable, machine-only authority control will link $95 \%$ or more of your library's controlled headings to an LC or LTI authority record. No exceptions! No excuses!

When manual review is requested, only professional librarians are used as editors and link rates approach $100 \%$.

LTI maintains the complete LC MARC authority files (updated weekly), supplemented with over 410,000 LTI authority records and 350,000 proprietary "cross links."

Contact LTI for more information on authority record link results.

"Authority Control for the 21st Century"

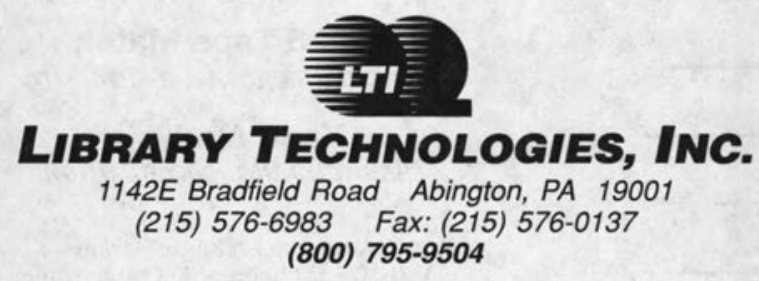

